\title{
Impacto das vazões demandadas pela irrigação e pelos abastecimentos animal e humano, na Bacia do Paracatu
}

\author{
Fernando F. Pruski', Renata del G. Rodriguez', Luciano F. de Novaes', \\ Demetrius D. da Silva ${ }^{1}$, Márcio M. Ramos ${ }^{1}$ \& Alessandro de F. Teixeira ${ }^{2}$
}

\begin{abstract}
RESUMO
O rio Paracatu é o afluente com maior contribuição para o rio São Francisco. Como conseqüência da grande expansão da agricultura irrigada na bacia do Paracatu, a partir da década de 70 sérios conflitos pelo uso da água surgiram em várias partes da bacia. Tendo em vista esses conflitos objetivou-se, com o presente trabalho, avaliar, ao longo da bacia do Paracatu, a proporção do consumo representado pela irrigação e pelos abastecimentos animal e humano e o impacto das vazões demandadas pela irrigação. A vazão média anual de longa duração, a vazão mínima de sete dias de duração e o período de retorno de 10 anos $\left(\mathrm{Q}_{7,10}\right)$ e a vazão associada à permanência de $95 \%\left(\mathrm{Q}_{95}\right)$ foram estimados utilizando-se o período de 1970 a $1996 \mathrm{em}$ 18 seções correspondentes a estações fluviométricas situadas na bacia do Paracatu. As vazões demandadas pelos segmentos analisados foram calculadas para o ano de 1996. Embora a vazão de retirada pela irrigação no mês de maior demanda, para as

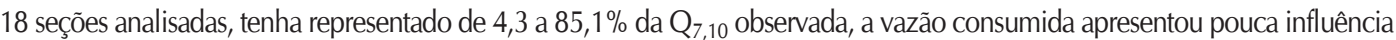
na vazão média de longa duração.
\end{abstract}

Palavras-chave: gestão de recursos hídricos, usos da água, disponibilidade hídrica

\section{Impact of water demands for irrigation, animal and human supply in the Paracatu Basin}

\begin{abstract}
The Paracatu River is the main tributary of the São Francisco River. As a consequence of the huge development of the irrigation in the Paracatu Basin, in the early 70 's, serious conflicts for the water use began to take place in several parts of the basin. The objectives of this paper were: to estimate the relative amount of the water consumption by irrigation and by animal and human supply in the Paracatu Basin; and to evaluate the impact of the water withdrawals for irrigation in the stream flow in the Paracatu River and tributaries. The average stream flow, the minimum stream flow of seven days and 10 years of return period $\left(Q_{7,10}\right)$ and the stream flow associated with the duration of $95 \%$ of permanence $\left(Q_{95}\right)$ were calculated from 1970 to 1996 for 18 stations used to measure the stream flow in the Paracatu Basin, and the water demand for the four sectors analyzed was calculated for 1996. Although the water withdrawals for irrigation in the month with the maximum demand have represented, for the 18 sections analyzed, from 4.3 to $85.1 \%$ of the $Q_{7,10}$, the water effectively consumed by irrigation did not have significant influence on the mean stream flow.
\end{abstract}

Key words: water resources management, water use, water availability 


\section{INTRODUÇÃO}

O aumento da demanda pelo uso da água, evidenciado nos últimos anos, vem causando sérios conflitos entre os seus usuários em muitas regiões da Terra fazendo, em muitos casos, com que a água se torne fator limitante para o desenvolvimento sustentável.

A bacia do São Francisco possui, segundo ANA (2002), uma demanda total de água de $224 \mathrm{~m}^{3} \mathrm{~s}^{-1}$, cujo principal usuário é a irrigação, responsável por $71,4 \%$ dessa demanda. A demanda total de outorgas para a retirada de água na bacia do São Francisco é, entretanto, da ordem de $770 \mathrm{~m}^{3} \mathrm{~s}^{-1}$, correspondente a $27 \%$ da vazão média na foz do rio, em que mais de $90 \%$ deste valor se destinam a projetos de irrigação (Lima et al., 1999). Ante valores tão expressivos, percebe-se a importância do estudo detalhado de cada pedido de outorga, visando minimizar os prejuízos socioeconômicos e ambientais advindos de retiradas excessivas de água.

A bacia do Paracatu, situada no Médio São Francisco, embora represente apenas $7,3 \%$ da área da bacia do São Francisco, drenando uma área de aproximadamente $45.600 \mathrm{~km}^{2}$ (Brasil, 1996), apresenta a maior proporção de contribuição $(20,8 \%)$ para a formação da vazão do rio São Francisco (Pereira, 2004).

Como conseqüência da grande expansão da agricultura irrigada nesta bacia, a partir da década de 70 sérios conflitos têm surgido, principalmente nas sub-bacias do ribeirão Entre Ribeiros e do rio Preto. Segundo Dino (2002), no caso do município de Paracatu houve necessidade, inclusive, de substituição do sistema de abastecimento de água, originalmente situado no córrego Espalha, para o córrego Santa Isabel, tendo em vista o impacto advindo dos projetos de irrigação implantados na área e que provocaram queda de vazão de 50 para $8 \mathrm{~L} \mathrm{~s}^{-1}$.

Tendo em vista o quadro de conflitos pelo uso da água existente na bacia do Paracatu teve-se, como objetivo, no presente trabalho, avaliar, ao longo da bacia do Paracatu, a pro- porção do consumo representado pela irrigação e pelos abastecimentos animal e humano (urbano e rural) e, ainda, avaliar o impacto das vazões demandadas pela irrigação na vazão média de longa duração e nas vazões mínimas.

\section{MATERIAL E MÉTODOS}

\section{Estimativa das vazões}

Estimou-se, com base no período de 1970 a 1996, a vazão média anual de longa duração, a vazão mínima de sete dias de duração e o período de retorno de 10 anos $\left(\mathrm{Q}_{7,10}\right)$ e a vazão associada à permanência de $95 \%$, com base em dados diários $\left(\mathrm{Q}_{95}\right)$ para 18 estações fluviométricas (Tabela 1) pertencentes à rede hidrometeorológica da Agência Nacional de Águas (ANA), situadas na bacia do Paracatu.

A $Q_{7,10}$ foi estimada a partir das distribuições de probabilidade de Weibull, Log-normal a dois e três parâmetros, Perason III e Log-Pearson tipo III, sendo selecionada a distribuição que apresentou o melhor ajuste à série histórica. Para esta seleção foram analisados o coeficiente de variação e o teste de Kolmogorov-Smirnov; já as vazões associadas à permanência de $95 \%$ foram obtidas pelas curvas de permanência de cada estação fluviométrica obtidas com base em dados diários, retratando a parcela de tempo em que determinada vazão foi igualada ou superada durante o período analisado.

Para a estimativa das vazões de retirada, de retorno e consumidas pelos quatro segmentos de usuários, foram consideradas, como vazões de retirada, as vazões captadas, vazões de retorno, as vazões lançadas nos corpos d'água após o seu uso e vazões consumidas que é a diferença entre as vazões de retirada e de retorno.

A estimativa das vazões de retirada, de retorno e consumidas pela irrigação, abastecimento animal e humano (urbano e rural) foi realizada para o Distrito Federal e para cada um dos 21 municípios pertencentes à área de drenagem corres-

Tabela 1. Estações fluviométricas utilizadas no estudo

\begin{tabular}{|c|c|c|c|c|c|}
\hline Código & Estação & Latitude & Longitude & Área de Drenagem $\left(\mathrm{km}^{2}\right)$ & Curso d’Água \\
\hline 42250000 & Fazenda Limoeiro & $17^{0} 54^{\prime} 56^{\prime \prime}$ & $47^{\circ} 00^{\prime} 38^{\prime \prime}$ & 470 & Rio Claro \\
\hline 42251000 & Fazenda Córrego do Ouro & $17^{\circ} 36^{\prime} 48^{\prime \prime}$ & $46^{\circ} 51^{\prime} 31^{\prime \prime}$ & 1840 & Rio Escuro \\
\hline 42255000 & Fazenda Nolasco & $17^{0} 13^{\prime} 48^{\prime \prime}$ & $47^{\circ} 01^{\prime} 20^{\prime \prime}$ & 257 & Ribeirão Santa Isabel \\
\hline 42257000 & Barra do Escurinho & $17^{\circ} 30^{\prime} 45^{\prime \prime}$ & $46^{\circ} 38^{\prime} 46^{\prime \prime}$ & 2.013 & Ribeirão Escurinho \\
\hline 42395000 & Santa Rosa & $17^{0} 15^{\prime} 19^{\prime \prime}$ & $46^{\circ} 28^{\prime} 26^{\prime \prime}$ & 12.880 & Rio Paracatu \\
\hline 42435000 & Fazenda Barra da Égua & $16^{\circ} 52^{\prime} 28^{\prime \prime}$ & $46^{\circ} 35^{\prime} 12^{\prime \prime}$ & 1.594 & Ribeirão Barra da Égua \\
\hline 42440000 & Fazenda Poções & $17^{\circ} 02^{\prime} 31^{\prime \prime}$ & $46^{\circ} 49^{\prime} 04^{\prime \prime}$ & 533 & Ribeirão São Pedro \\
\hline 42460000 & Fazenda Limeira & $16^{\circ} 12^{\prime} 35^{\prime \prime}$ & $47^{0} 13^{\prime} 58^{\prime \prime}$ & 3.830 & Rio Preto \\
\hline 42490000 & Unaí & $16^{\circ} 20^{\prime} 58^{\prime \prime}$ & $46^{\circ} 52^{\prime} 48^{\prime \prime}$ & 5.250 & Rio Preto \\
\hline 42540000 & Santo Antônio do Boqueirão & $16^{\circ} 31^{\prime} 47^{\prime \prime}$ & $46^{\circ} 43^{\prime} 16^{\prime \prime}$ & 5.840 & Rio Preto \\
\hline 42545500 & Fazenda o Resfriado & $16^{\circ} 30^{\prime} 10^{\prime \prime}$ & $46^{\circ} 39^{\prime} 46^{\prime \prime}$ & 704 & Ribeirão Roncador \\
\hline 42546000 & Fazenda Santa Cruz & $16^{\circ} 08^{\prime} 06^{\prime \prime}$ & $46^{\circ} 44^{\prime} 52^{\prime \prime}$ & 530 & Rio Salobro \\
\hline 42600000 & Porto dos Poções & $16^{\circ} 50^{\prime} 23^{\prime \prime}$ & $46^{\circ} 21^{\prime} 26^{\prime \prime}$ & 9.370 & Rio Preto \\
\hline 42750000 & Caatinga & $17^{\circ} 08^{\prime} 45^{\prime \prime}$ & $45^{\circ} 52^{\prime} 49^{\prime \prime}$ & 30.230 & Rio Paracatu \\
\hline 42840000 & Veredas & $18^{\circ} 08^{\prime} 19^{\prime \prime}$ & $45^{\circ} 45^{\prime} 32^{\prime \prime}$ & 190 & Rio Santo Antônio \\
\hline 42850000 & Cachoeira das Almas & $17^{\circ} 21^{\prime} 02 "$ & $45^{\circ} 31^{\prime} 57^{\prime \prime}$ & 4.350 & Rio do Sono \\
\hline 42860000 & Cachoeira do Paredão & $17^{\circ} 07^{\prime} 16^{\prime \prime}$ & $45^{\circ} 26^{\prime} 08^{\prime \prime}$ & 5.660 & Rio do Sono \\
\hline 42980000 & Porto Alegre & $16^{\circ} 46^{\prime} 29^{\prime \prime}$ & $45^{\circ} 22^{\prime} 55^{\prime \prime}$ & 40.300 & Rio Paracatu \\
\hline
\end{tabular}


pondente às 18 estações fluviométricas. Obteve-se a vazão de retirada para cada tipo de usuário pelo somatório das vazões relativas a todos os municípios pertencentes à área de drenagem considerada.

Apresentam-se, na Figura 1, os municípios pertencentes à bacia e suas respectivas sedes.

No cálculo da vazão de retirada para o abastecimento urbano considerou-se que, se a sede do município se encontra na área de drenagem analisada, toda população atendida está na área de drenagem e, portanto, toda a vazão de retirada foi computada nesta área de drenagem. Para o cálculo da vazão de retirada pela irrigação e para os abastecimentos animal e rural, considerou-se o critério de proporcionalidade da área do município, localizada na área de drenagem considerada.
As vazões consumidas pela irrigação e pelo abastecimento animal foram estimadas pelo censo agropecuário (IBGE, 1996); entretanto, em virtude da inexistência de censos demográficos do IBGE no referido ano, estimaram-se as vazões consumidas pelo abastecimento humano (urbano e rural) para os anos de 1991 e 2000 (último ano do censo demográfico) (IBGE, 1991 e 2000) e, por meio de interpolação desses dados de vazões, obtiveram-se as vazões para o ano de 1996.

$\mathrm{Na}$ seqüência, descreve-se o procedimento utilizado para o cálculo das vazões consumidas para cada um dos quatro segmentos de usuários considerados neste estudo.

\section{Irrigação}

A vazão de retirada pela irrigação foi estimada com base $48^{\circ}$

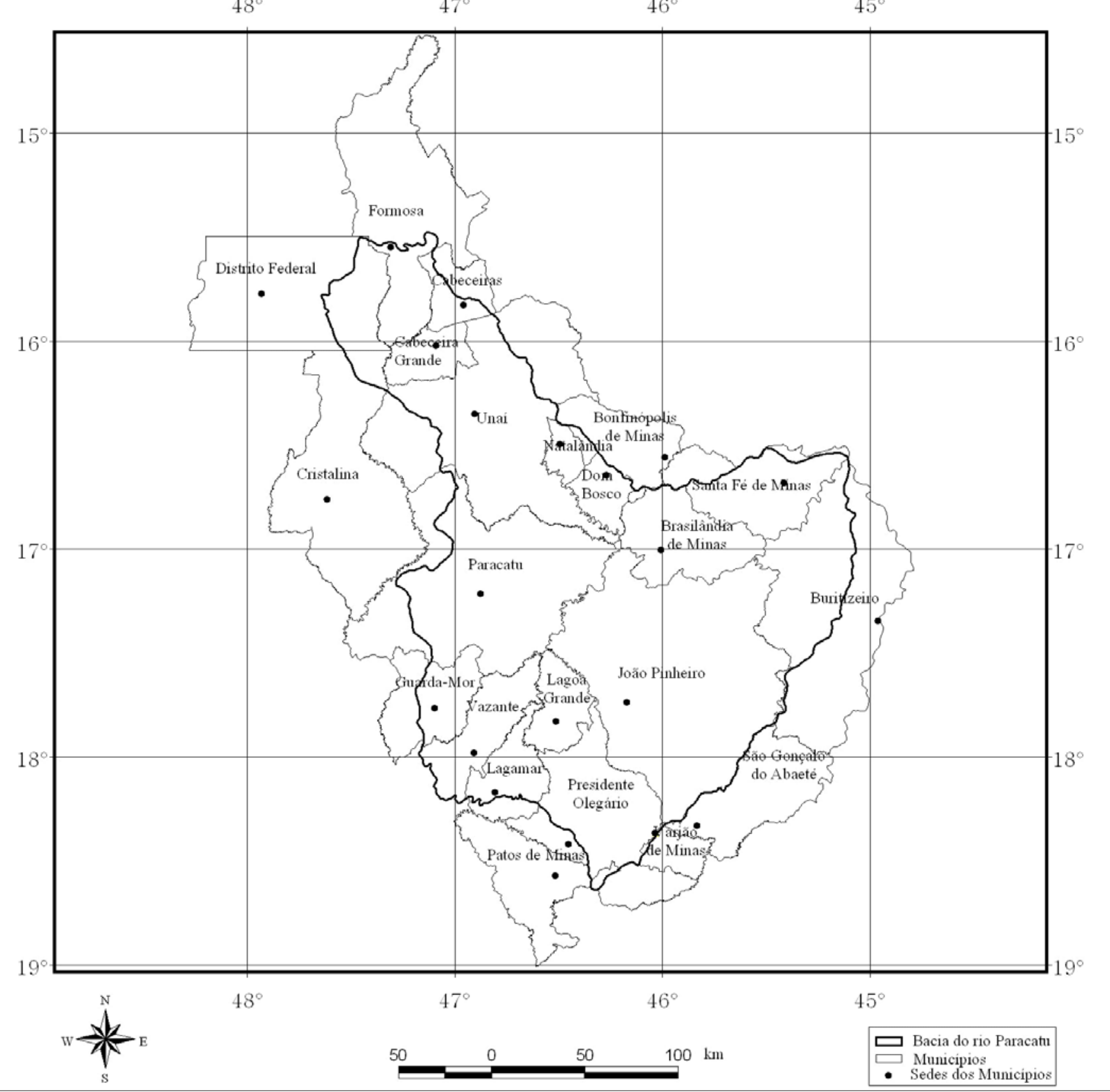

Figura 1. Localização dos municípios pertencentes à bacia do Paracatu e das respectivas sedes e do contorno da bacia 
na irrigação total necessária e na área irrigada para cada cultura em cada mês no município, determinada pela equação

$$
\mathrm{Q}_{\mathrm{m}, \mathrm{i}}=\sum_{\mathrm{i}=1}^{\mathrm{cn}}\left[\frac{\mathrm{ET}_{\mathrm{rc}, \mathrm{m}, \mathrm{m}}-\mathrm{P}_{\mathrm{ef}, \mathrm{m}, \mathrm{m}}}{\mathrm{E}_{\mathrm{a}}}\right] \mathrm{A}_{\mathrm{m}, \mathrm{i}, \mathrm{c}, \mathrm{m}} 10.000
$$

em que:

$\mathrm{Q}_{\mathrm{m}, \mathrm{i}}$ - vazão de retirada pela irrigação no município, $\mathrm{L} \mathrm{d}^{-1}$

$\mathrm{ET}_{\mathrm{rc}, \mathrm{m}, \mathrm{m}}$ - evapotranspiração real da cultura para cada mês no município, $\mathrm{mm} \mathrm{d}^{-1}$

$\mathrm{P}_{\mathrm{ef}, \mathrm{m}, \mathrm{m}}$ - precipitação efetiva mensal no município, $\mathrm{mm} \mathrm{d}^{-1}$

$\mathrm{E}_{\mathrm{a}}$ - eficiência de aplicação, adimensional

$\mathrm{A}_{\mathrm{m}, \mathrm{i}, \mathrm{c}, \mathrm{m}}$ - área irrigada para a cultura no município e em cada mês, ha

$\mathrm{Cn}$ - número de culturas irrigadas no município

As áreas irrigadas mensalmente para cada cultura, foram calculadas a partir dos dados obtidos no censo agropecuário de 1996, utilizando-se o procedimento apresentado por Rodriguez (2004). A evapotranspiração real das culturas foi estimada com base na evapotranspiração potencial da cultura de referência, calculada pelo método de Penman-Monteith, nos coeficientes das culturas $\left(\mathrm{K}_{\mathrm{c}}\right)$ e no coeficiente que depende da umidade do solo $\left(\mathrm{K}_{\mathrm{s}}\right)$.

Para cada cultura foi associado o método de irrigação de uso mais freqüente, sendo o método de irrigação por aspersão associado às culturas temporárias e o de irrigação localizada às culturas permanentes. Considerando-se os resultados obtidos por Ramos \& Pruski (2003) em estudo pertinente à quantificação e análise da eficiência do uso da água pelo setor agrícola na bacia do São Francisco, adotaram-se os valores de 0,81 e 0,88 para o $K_{s}$ e de 0,70 e 0,79 para a $E_{a}$ para as irrigações por aspersão e localizada, respectivamente. A precipitação efetiva foi obtida pelo método proposto pelo boletim 24 da FAO (Doorenbos \& Pruitt, 1977).

As perdas por percolação e escoamento ocorridas na aplicação da água para cada tipo de irrigação, foram consideradas como retorno, não se levando em conta as perdas ocorridas na condução da água; portanto, a vazão de retorno foi obtida pela equação.

$\mathrm{Q}_{\mathrm{m}, \mathrm{i}, \mathrm{r}}=\sum_{\mathrm{i}=1}^{\mathrm{cn}}\left[\frac{\mathrm{ET} \mathrm{T}_{\mathrm{rc}, \mathrm{m}, \mathrm{m}}-\mathrm{P}_{\mathrm{ef}, \mathrm{m}, \mathrm{m}}}{\mathrm{E}_{\mathrm{a}}}\right] \mathrm{A}_{\mathrm{m}, \mathrm{i}, \mathrm{c}, \mathrm{m}} 10.000\left(\mathrm{P}_{\mathrm{p}}+\mathrm{P}_{\mathrm{esc}}\right)$

em que:

$\mathrm{Q}_{\mathrm{m}, \mathrm{i}, \mathrm{r}}$ - vazão de retorno referente à irrigação no município, $\mathrm{L} \mathrm{d}^{-1}$

$\mathrm{P}_{\mathrm{p}}$ - perdas por percolação, adimensional

$\mathrm{P}_{\mathrm{esc}}$ - perdas por escoamento, adimensional

Considerou-se que não seria irrigada a cultura, caso a precipitação efetiva fosse maior que a evapotranspiração real da cultura, enquanto as perdas por percolação mais as perdas por escoamento, foram estimadas pela equação.

$$
\left(\mathrm{P}_{\mathrm{p}}+\mathrm{P}_{\mathrm{esc}}\right)=1-\mathrm{P}_{\mathrm{evp}}-\mathrm{E}_{\mathrm{a}}
$$

em que:

$\mathrm{P}_{\text {evp }}$ - são as perdas por evaporação e deriva, adimensional.

Para os sistemas de irrigação por aspersão, adotou-se uma perda por evaporação e deriva igual a 10,9\% (Ramos \& Pruski, 2003), enquanto para os sistemas de irrigação localizada esta perda foi considerada nula.

\section{Abastecimento animal}

A vazão de retirada para o abastecimento animal foi obtida pela equação.

$$
\mathrm{Q}_{\mathrm{m}, \mathrm{a}}=\left(\mathrm{P}_{\mathrm{m}, \mathrm{ay}} \mathrm{q}_{\mathrm{a}, \mathrm{y}}\right)
$$

em que:

$\mathrm{Q}_{\mathrm{m}, \mathrm{a}}$ - vazão de retirada para o abastecimento animal no município, $\mathrm{L} \mathrm{d}^{-1}$

$\mathrm{P}_{\mathrm{m} \text {,ay }}$ - número de cabeças do rebanho para cada espécie animal no município, cab

$\mathrm{q}_{\text {ay }}$ - vazão per capita para cada espécie animal, $\mathrm{L} \mathrm{d}^{-1} \mathrm{cab}^{-1}$

Para determinação da vazão per capita correspondente a cada espécie animal, utilizaram-se os critérios propostos pelo MMA (2003), no qual se adotou a vazão per capita por espécie animal, contida em Rebouças et al. (1999). A vazão per capita para aves, não disponível no trabalho desses autores, foi obtida em Corsan (1991). Com o intuito de uma estimativa melhor da vazão de retorno que expresse principalmente as condições de confinamento (suínos, bovinos etc.), em que esta vazão pode representar uma parcela expressiva de vazão de retirada, considerou-se a vazão de retorno como $20 \%$ da vazão de retirada.

\section{Abastecimento urbano}

A vazão de retirada para o abastecimento urbano em cada município foi obtida pela equação.

$$
\mathrm{Q}_{\mathrm{m}, \mathrm{u}}=\left(\mathrm{P}_{\mathrm{m}, \mathrm{u}, \mathrm{a}} \mathrm{q}_{\mathrm{m}, \mathrm{u}}\right)
$$

em que:

$\mathrm{Q}_{\mathrm{m}, \mathrm{u}}$ - vazão de retirada para o abastecimento humano urbano no município, $\mathrm{L} \mathrm{d}^{-1}$

$\mathrm{P}_{\mathrm{m}, \mathrm{u}, \mathrm{a}}$ - população urbana do município abastecida pelo Sistema Público de Abastecimento de Água, hab

$\mathrm{q}_{\mathrm{m}, \mathrm{u}}$ - vazão per capita para o município, L hab $\mathrm{h}^{-1} \mathrm{~d}^{-1}$

Quando a população abastecida foi maior que a urbana considerou-se, como população urbana abastecida pelo Sistema Público de Abastecimento de Água, a própria população urbana porém, quando a população abastecida foi menor que a urbana, considerou-se toda a população abastecida como a população urbana abastecida.

Tendo em vista a inexistência de dados referentes à população abastecida pelo Sistema Público de Abastecimento de Água nos censos demográficos, esta foi estimada pela equação. 


$$
\mathrm{P}_{\mathrm{m}, \mathrm{a}}=\mathrm{D}_{\mathrm{m}, \mathrm{a}} \frac{\mathrm{P}_{\mathrm{m}, \mathrm{u}}}{\mathrm{D}_{\mathrm{m}, \mathrm{u}}}
$$

em que:

$\mathrm{P}_{\mathrm{m}, \mathrm{a}}$ - população abastecida pelo Sistema Público de Abas tecimento de Água no município, hab

$\mathrm{D}_{\mathrm{m}, \mathrm{u}}$ - domicílios urbanos no município, unidade (obtidos nos censos demográficos do IBGE)

$\mathrm{D}_{\mathrm{m}, \mathrm{a}}$ - domicílios abastecidos pelo Sistema Público de Abas tecimento no município, unidade (obtidos nos censos demográficos do IBGE)

$\mathrm{P}_{\mathrm{m}, \mathrm{u}}$ - população urbana no município, hab (obtida nos cen sos demográficos do IBGE)

A vazão per capita para os municípios cujas sedes se localizam dentro da bacia do Paracatu, foi estimada pela equação.

$$
\mathrm{q}_{\mathrm{m}, \mathrm{u}}=\frac{\mathrm{V}_{\mathrm{m}, \mathrm{u}, \mathrm{d}}}{\mathrm{P}_{\mathrm{m}, \mathrm{u}, \mathrm{a}}}
$$

em que:

$\mathrm{q}_{\mathrm{m}, \mathrm{u}}$ - vazão per capita no município, $\mathrm{L}$ hab $\mathrm{b}^{-1} \mathrm{~d}^{-1}$

$\mathrm{V}_{\mathrm{m}, \mathrm{u}, \mathrm{d}}$ - volume de água distribuído no município, $\mathrm{L} \mathrm{d}^{-1}$

A Norma Brasileira 9649 da ABNT recomenda, na falta de valores experimentais, o valor de 0,8 para o coeficiente de retorno (Alem Sobrinho \& Tsutiya, 1999).

\section{Abastecimento humano rural}

A vazão de retirada para abastecimento rural, por município, foi estimada considerando-se duas situações: população abastecida pelo sistema público maior que a população urbana e menor que a população urbana.

Quando população abastecida pelo sistema público foi maior que a população urbana, considerou-se que parte da população rural do município estava sendo abastecida pelo Sistema Público de Abastecimento de Água; logo, a população considerada no abastecimento rural do município foi estimada tendo em vista toda a população rural como a abastecida quanto a não-abastecida; então, a vazão retirada para o abastecimento rural no município foi estimada pela equação.

$$
\mathrm{Q}_{\mathrm{m}, \mathrm{r}}=\mathrm{P}_{\mathrm{m}, \mathrm{r}, \mathrm{a}} \mathrm{q}_{\mathrm{m}, \mathrm{u}}+\mathrm{P}_{\mathrm{m}, \mathrm{r}, \mathrm{n} a} \mathrm{q}_{\mathrm{m}, \mathrm{r}}
$$

em que:

$\mathrm{Q}_{\mathrm{m}, \mathrm{r}}$ - vazão de retirada para o abastecimento rural no município, $\mathrm{L} \mathrm{d}^{-1}$

$\mathrm{P}_{\mathrm{m}, \mathrm{r}, \mathrm{a}}$ - população residente no meio rural, abastecida pelo Sistema Público de Abastecimento de Água, hab

$\mathrm{P}_{\mathrm{m}, \mathrm{r}, \text { ña }}$ - população residente no meio rural não-abastecida pelo Sistema Público de Abastecimento de Água, hab

$\mathrm{q}_{\mathrm{m}, \mathrm{r}}$ - vazão per capita no meio rural, $\mathrm{L}$ hab $\mathrm{b}^{-1} \mathrm{~d}^{-1}$

A população rural abastecida pelo Sistema Público de Abastecimento de Água no município, foi obtida pela equação:

$$
\mathrm{P}_{\mathrm{m}, \mathrm{r}, \mathrm{a}}=\mathrm{P}_{\mathrm{m}, \mathrm{a}}-\mathrm{P}_{\mathrm{m}, \mathrm{u}}
$$

A população rural não-abastecida pelo Sistema Público de Abastecimento de Água, foi estimada pela equação.

$$
\mathrm{P}_{\mathrm{m}, \mathrm{r}, \mathrm{n} a}=\mathrm{P}_{\mathrm{m}, \mathrm{t}}-\mathrm{P}_{\mathrm{m}, \mathrm{a}}
$$

em que $\mathrm{P}_{\mathrm{m}, \mathrm{t}}$ é população total do município, hab (obtida nos censos demográficos do IBGE).

Para determinação da vazão per capita no meio rural, utilizaram-se os critérios propostos pela ANA (2003) no documento "Base de Referência para o Plano Nacional de Recursos Hídricos".

Quando a população abastecida pelo sistema público foi menor que a população urbana, a vazão retirada para o abastecimento rural no município foi estimada pela equação.

$$
\mathrm{Q}_{\mathrm{m}, \mathrm{r}}=\mathrm{P}_{\mathrm{m}, \mathrm{rt}} \mathrm{q}_{\mathrm{m}, \mathrm{r}}
$$

em que $\mathrm{P}_{\mathrm{m}, \mathrm{rt}}$ é população total considerada para o abastecimento rural no município, hab.

A população considerada no cálculo do abastecimento rural no município, foi estimada pela equação:

$$
\mathrm{P}_{\mathrm{m}, \mathrm{rt}}=\mathrm{P}_{\mathrm{m}, \mathrm{r}}+\mathrm{P}_{\mathrm{m}, \mathrm{u}, \text { ña }}
$$

em que:

$\mathrm{P}_{\mathrm{m}, \mathrm{r}}$ - população residente no meio rural no município, hab

$\mathrm{P}_{\mathrm{m}, \mathrm{u}, \mathrm{na} a}$ - população urbana não-abastecida pelo sistema pú-

blico de abastecimento de água no município, hab

A população urbana não-abastecida, foi estimada pela equação:

$$
\mathrm{P}_{\mathrm{m}, \mathrm{u}, \mathrm{n} a}=\mathrm{P}_{\mathrm{m}, \mathrm{u}}-\mathrm{P}_{\mathrm{m}, \mathrm{a}}
$$

O fato de, em geral, inexistirem sistemas para a condução das vazões de retorno aos mananciais de águas superficiais no meio rural, implica na inexistência do retorno das vazões de retirada, uma vez que este passa a ocorrer através do reabastecimento do lençol freático e conseqüente escoamento subterrâneo. Embora se reconheça que o retorno deva ser inferior ao do abastecimento urbano, considera-se que ele não deva ser desprezado. Pela consulta à literatura, não foi possível identificar nenhum valor de referência para este coeficiente; entretanto, acredita-se que um valor da ordem de 0,5 possa constituir um referencial para início de análise; daí, a vazão de retorno foi considerada igual a $50 \%$ da vazão de retirada.

\section{Estimativa das vazões naturais}

Para estimativa das vazões naturais, utilizou-se a Equação 14.

R. Bras. Eng. Agríc. Ambiental, v.11, n.2, p.199-210, 2007. 


$$
\mathrm{Q}_{\text {nat }}=\mathrm{Q}_{\mathrm{obs}}+\mathrm{Q}_{\mathrm{anim}}+\mathrm{Q}_{\mathrm{rur}}+\mathrm{Q}_{\mathrm{urb}}+\mathrm{Q}_{\text {irrig }}
$$

em que:

$$
\begin{aligned}
& \mathrm{Q}_{\text {nat }} \text { - vazão diária natural, } \mathrm{m}^{3} \mathrm{~s}^{-1} \\
& \mathrm{Q}_{\text {obs }} \text { - vazão diária observada, } \mathrm{m}^{3} \mathrm{~s}^{-1} \\
& \mathrm{Q}_{\text {anim }} \text { - vazão média mensal consumida pelo abasteciento } \\
& \text { animal, } \mathrm{m}^{3} \mathrm{~s}^{-1}
\end{aligned}
$$

\section{RESULTADOS E DISCUSSÃO}

\section{Vazões consumidas}

A Figura 2 apresenta, para o ano de 1996, as vazões consumidas pela irrigação e pelos abastecimentos animal e humano (urbano e rural), bem como as proporções associadas a cada um desses usuários.

A vazão consumida pela irrigação foi superior a $78 \%$ do total consumido em todas as seções analisadas. Para o abastecimento animal, a vazão consumida variou de 6 a $21 \%$ do total, para abastecimento humano urbano de 1 a $5 \%$ e, para o abastecimento humano rural, inferior a $2 \%$.

Na estação Porto Alegre, mais próxima do desagüe do rio Paracatu no São Francisco, a qual representa $88 \%$ da área de drenagem total da bacia e até onde se encontravam em 1996, $99,6 \%$ da área irrigada da bacia, a vazão consumida foi de 5,15 $\mathrm{m}^{3} \mathrm{~s}^{-1}$; desse total, $4,46 \mathrm{~m}^{3} \mathrm{~s}^{-1}(87 \%)$ foram consumidos pela irrigação, $0,55 \mathrm{~m}^{3} \mathrm{~s}^{-1}(11 \%)$ pelo abastecimento animal, $0,08 \mathrm{~m}^{3}$ $\mathrm{s}^{-1}(2 \%)$ pelo abastecimento urbano e $0,063 \mathrm{~m}^{3} \mathrm{~s}^{-1}(1 \%)$ pelo abastecimento rural.

A maior proporção de consumo pela irrigação foi evidenciada nas regiões oeste e noroeste, principalmente no ribeirão Entre Ribeiros e afluentes, no rio Preto e afluentes e no ribeirão Santa Isabel, afluente do rio Escuro, sendo a irrigação responsável por mais de $92 \%$ do total consumido no Entre Ribeiros, $85 \%$ no rio Preto e afluentes e $93 \%$ no ribeirão Santa Isabel.

A comparação dos valores obtidos nas áreas de drenagem das estações Porto dos Poções (rio Preto), Fazenda Barra da Égua e Fazenda Poções (ambas situadas na sub-bacia do ribeirão Entre Ribeiros), nas quais se concentravam $46 \%$ da área irrigada da bacia e a vazão consumida pela irrigação, era de $1,8 \mathrm{~m}^{3} \mathrm{~s}^{-1}$ (41\% da vazão consumida pela irrigação na bacia), com os valores apresentados no Plano Diretor de Recursos Hídricos - PLANPAR, no qual se notou que as bacias dos rios Preto e Entre Ribeiros concentravam 53\% $\left(206,9 \mathrm{~km}^{2}\right)$ do total das áreas irrigadas na bacia do Paracatu, permitiu evidenciar boa proximidade entre as duas estimativas.

Em relação ao abastecimento animal, as maiores proporções consumidas foram evidenciadas nas regiões central e sul da bacia, decorrentes sobretudo dos grandes rebanhos bovinos existentes nos municípios de João Pinheiro e Paracatu, situados nesta região, os quais representavam 23\% (246.676 cabe- ças) e $16 \%$ (178.378 cabeças), respectivamente, do rebanho bovino da bacia.

As maiores proporções de consumo pelo abastecimento humano (urbano e rural) foram observadas nas regiões noroeste e oeste da bacia. Em virtude dos censos demográficos terem sido realizados para os anos de 1991 e 2000 não havendo, portanto, censo em 1996, os dados referentes às populações, apresentados na seqüência, são relativos a 2000, último ano de censo. Na região noroeste, onde se localizam os municípios de Formosa e Unaí, viviam 28\% (48.862 hab) da população urbana abastecida pelo sistema público, a qual era responsável por $45 \%\left(0,055 \mathrm{~m}^{3} \mathrm{~s}^{-1}\right)$ do total consumido de água por esse segmento na bacia e $17 \%$ (13.318 hab) da população rural da bacia, respondendo por $14 \%\left(0,018 \mathrm{~m}^{3} \mathrm{~s}^{-1}\right)$ do consumo total de água por este segmento na bacia. $\mathrm{Na}$ região oeste, onde se localiza o município de Paracatu, viviam 27\% (47.008 hab) da população urbana abastecida, a qual era responsável por $25 \%\left(0,031 \mathrm{~m}^{3} \mathrm{~s}^{-1}\right)$ do consumo de água

Tabela 2. Vazão consumida no ano de 1996, vazão média de longa duração e porcentagem das vazões consumidas em relação à vazão média de longa duração, nas 18 estação analisadas

\begin{tabular}{cccc}
\hline Código & $\begin{array}{c}\text { Vazão Média de } \\
\text { Longa Duração } \\
\left(\mathbf{m}^{3} \mathbf{s}^{-1}\right)\end{array}$ & $\begin{array}{c}\text { Vazão } \\
\text { Consumida } \\
\left(\mathbf{m}^{3} \mathbf{s}^{-1}\right)\end{array}$ & $\left(\frac{\text { Vazão Consumida }}{\text { Vazão média de longa duração }}\right) 100$ \\
\hline 42250000 & 8,37 & 0,045 & 0,54 \\
\hline 42251000 & 29,31 & 0,255 & 0,87 \\
\hline 42255000 & 3,45 & 0,049 & 1,43 \\
\hline 42257000 & 27,84 & 0,488 & 1,75 \\
\hline 42395000 & 163,82 & 1,564 & 0,96 \\
\hline 42435000 & 18,86 & 0,394 & 2,09 \\
\hline 42440000 & 10,34 & 0,103 & 1,00 \\
\hline 42460000 & 61,06 & 0,597 & 0,98 \\
\hline 42490000 & 77,57 & 0,770 & 0,99 \\
\hline 42540000 & 89,25 & 0,936 & 1,05 \\
\hline 42545500 & 9,36 & 0,137 & 1,47 \\
\hline 42546000 & 8,01 & 0,128 & 1,59 \\
\hline 42600000 & 125,00 & 1,571 & 1,26 \\
\hline 42750000 & 370,98 & 4,385 & 1,28 \\
\hline 42840000 & 3,45 & 0,017 & 0,49 \\
\hline 42850000 & 65,01 & 0,400 & 0,62 \\
\hline 42860000 & 70,86 & 0,465 & 0,66 \\
\hline 42980000 & 494,56 & 5,154 & 1,04 \\
\hline
\end{tabular}

por este segmento na bacia e $14 \%$ da população rural (10.859 hab) da bacia, responsável por $8 \%\left(0,010 \mathrm{~m}^{3} \mathrm{~s}^{-1}\right)$ do consumo de água por este segmento na bacia.

\section{Impacto na vazão média de longa duração}

Apresentam-se, na Tabela 2, para as 18 estações fluviométricas analisadas, as vazões consumidas no ano de 1996 pelos quatro segmentos de usuários, as vazões médias de longa duração e as proporções das vazões consumidas em relação às vazões médias de longa duração e se verifica, também, que as vazões consumidas foram, em geral, pouco expressivas em relação à vazão média de longa duração do rio, representando de 0,5 a $2,1 \%$ das vazões dos rios, nas seções analisadas. 


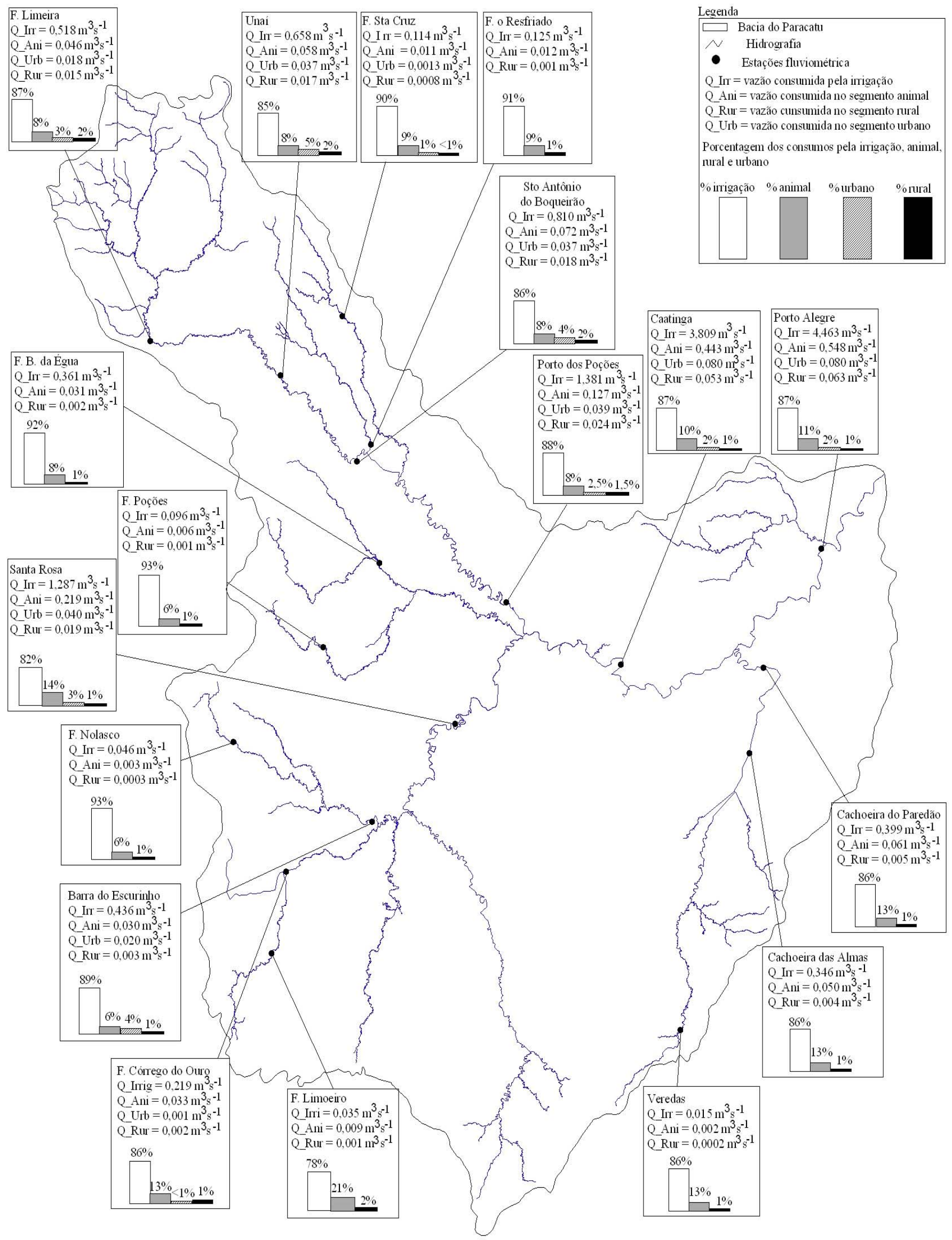

Figura 2. Vazões consumidas pela irrigação e pelos abastecimentos animal e humano (urbano e rural) e respectivas porcentagens em relação ao total consumido no ano de 1996, na área de drenagem das 18 estações analisadas 


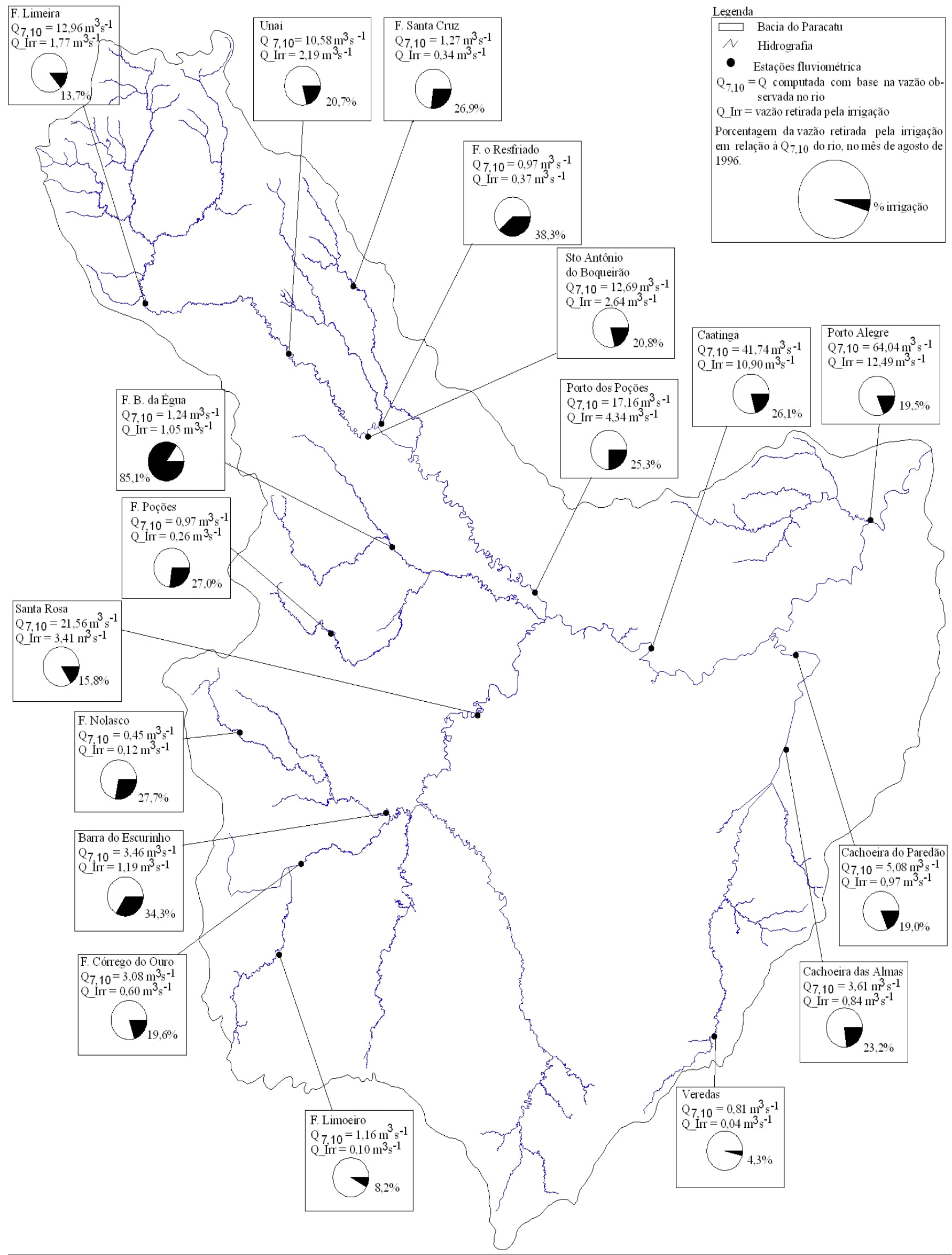

Figura 3. Vazões de retirada pela irrigação em 1996, no mês de maior demanda (agosto), $Q_{7,10}$ estimada com base na vazão observada e porcentagens das vazões de retirada em relação às $Q_{7,10}$ observadas 


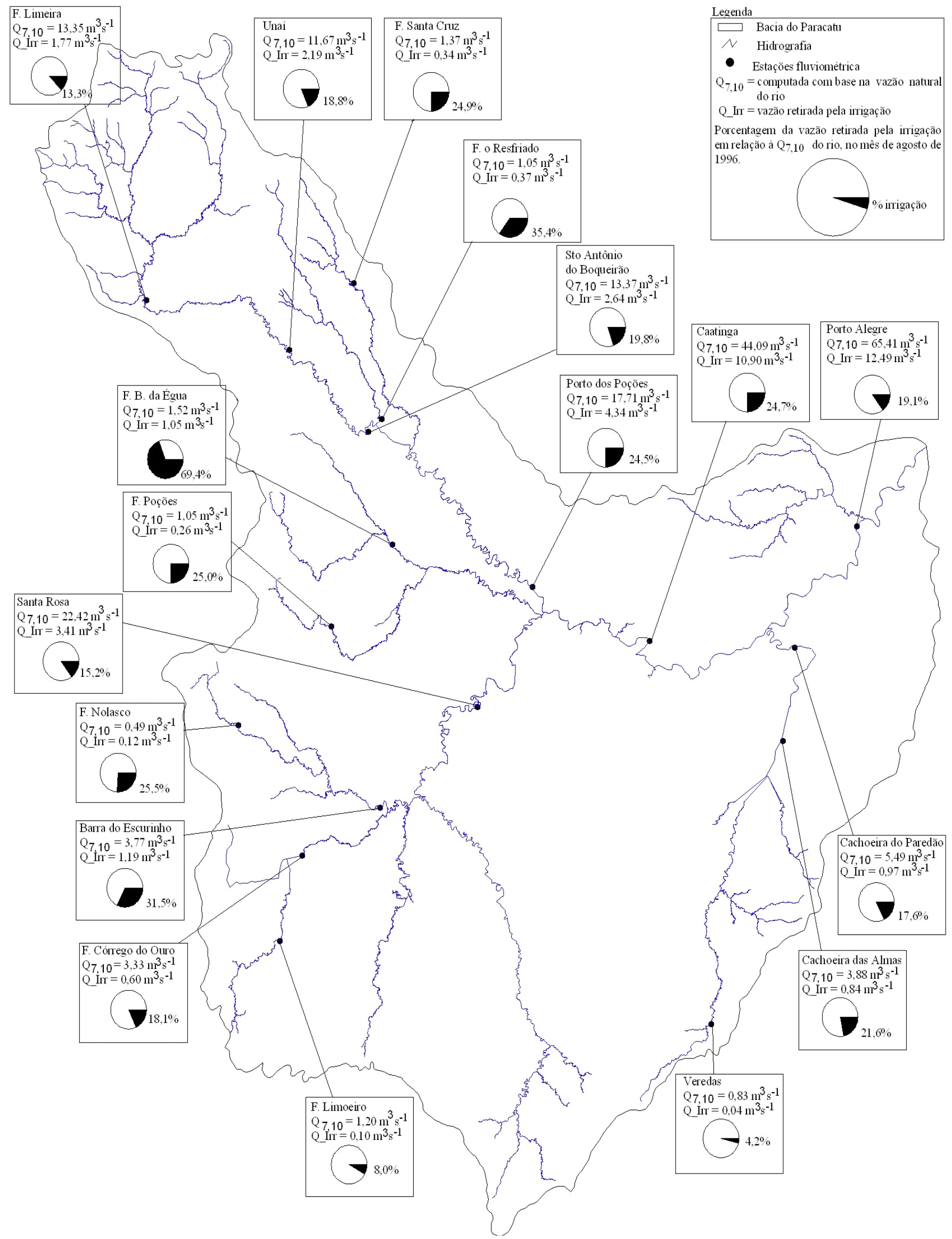

Figura 4. Vazões de retirada para irrigação em 1996, no mês de maior demanda (agosto), $\mathrm{Q}_{7,10}$ estimada com base na vazão natural e porcentagens das vazões de retirada em relação às $Q_{7,10}$ naturais 


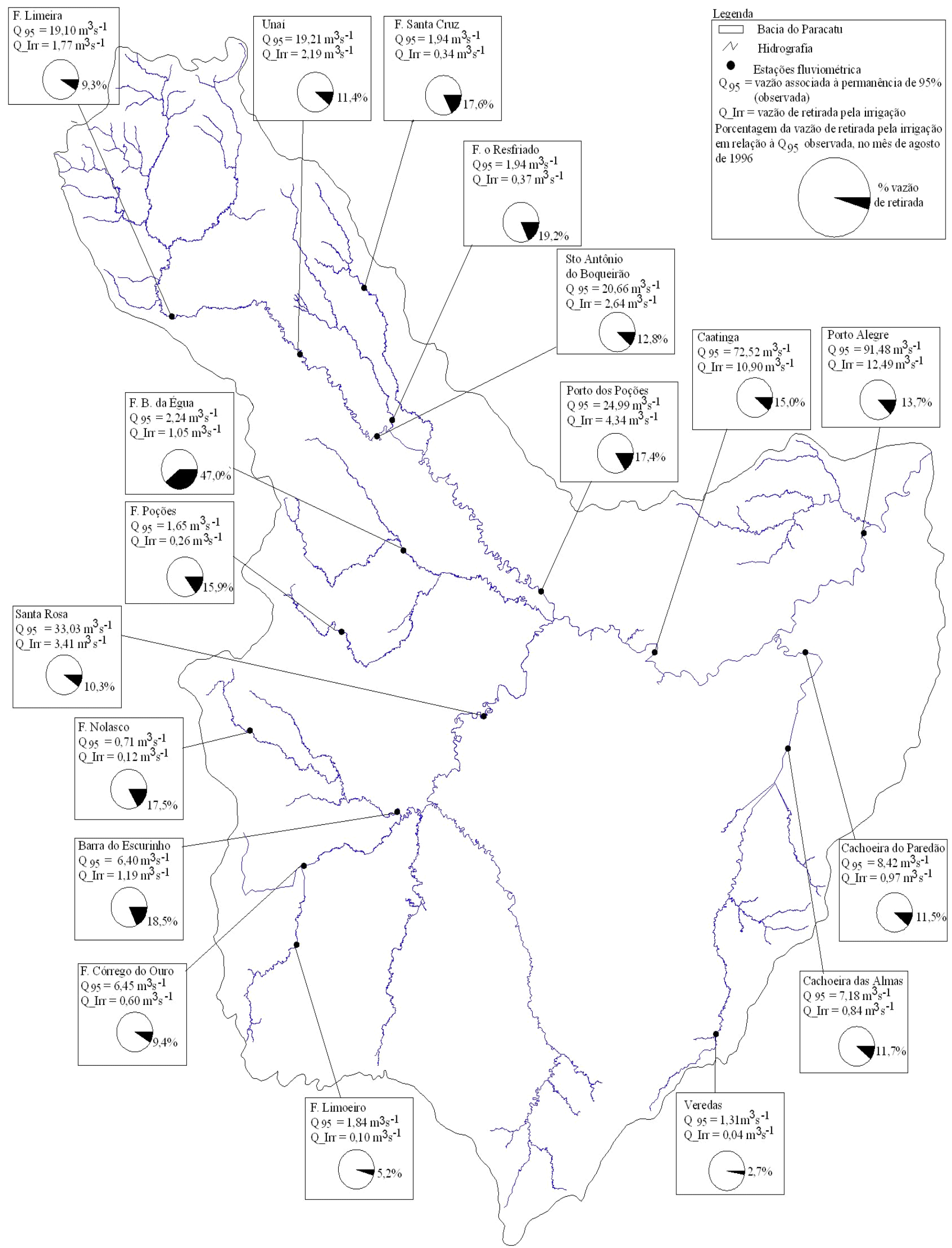

Figura 5. Vazões de retirada para irrigação em 1996 no mês de maior demanda (agosto), $\mathrm{Q}_{95}$ estimada com base na vazão observada e porcentagens das vazões de retirada em relação às $\mathrm{Q}_{95}$ observadas 
Na seção localizada mais à jusante do rio Paracatu, a qual representa o comportamento geral da bacia, a vazão consumida no ano de 1996 correspondeu a apenas 1\% da vazão média de longa duração observada no rio.

O maior consumo de água em relação à vazão média de longa duração foi evidenciado no ribeirão Entre Ribeiros, representando $2,1 \%$. Conforme já mencionado, referido consumo ocorreu devido ao grande uso da irrigação nesta sub-bacia.

A pequena proporção das vazões médias de longa duração, consumidas pela irrigação, indicou a existência de um potencial para a construção de reservatórios de acumulação, os quais poderão permitir o crescimento das atividades econômicas na bacia, sem comprometer a sustentabilidade desse desenvolvimento.

\section{Impacto da vazão retirada pela irrigação}

Sendo a irrigação o principal consumidor de água na bacia do Paracatu, na Figura 3 se apresentam as vazões de retirada pela irrigação no mês de maior demanda (agosto) de 1996, as vazões referentes à $\mathrm{Q}_{7,10}$, estimada com base na vazão observada no rio no período de 1970 a 1996, e os percentuais das vazões retiradas pela irrigação em relação à $\mathrm{Q}_{7,10}$ observada. Nesta figura, evidencia-se que as vazões de retirada pela irrigação no mês de maior demanda variaram de 4,3\% (Veredas) a 85,1\% (Fazenda Barra da Égua).

A maior porcentagem da vazão de retirada pela irrigação $\left(1,05 \mathrm{~m}^{3} \mathrm{~s}^{-1}\right)$ em relação à $\mathrm{Q}_{7,10}$ observada foi de $85,1 \%$, evidenciada na seção Fazenda Barra da Égua, localizada no ribeirão Entre Ribeiros. Este percentual foi muito superior ao da máxima vazão concedida para outorga no Estado de Minas Gerais (onde se encontra o ribeirão Entre Ribeiros), que é de $30 \%$ da $\mathrm{Q}_{7,10}$.

Visando a uma comparação entre os resultados obtidos da relação das vazões consumidas pela irrigação e as $\mathrm{Q}_{7,10} \mathrm{ob}-$ servadas, com aqueles da relação das vazões consumidas pela irrigação e as $\mathrm{Q}_{7,10}$ naturais, apresentam-se, na Figura 4, as vazões de retirada para irrigação no mês de maior demanda (agosto) de 1996, as $\mathrm{Q}_{7,10}$ estimadas com base na vazão natural do rio no período de 1970 a 1996 (Q ${ }_{7,10}$ natural) e as porcentagens das vazões retiradas para irrigação em relação à $\mathrm{Q}_{7,10}$ natural. Nesta figura se verifica que as vazões de retirada pela irrigação representam de 4,2 a 69,4\% da $\mathrm{Q}_{7,10}$ natural, parcelas que, embora inferiores àquelas obtidas em relação à $\mathrm{Q}_{7,10}$ observada, ainda são muito expressivas em relação à vazão do rio e, em certas seções, muito superiores às vazões máximas permissíveis para outorga.

Enquanto em estações como Porto Alegre e Veredas a redução da proporção $\left(\mathrm{Q}_{\text {irr }} / \mathrm{Q}_{7,10 \text { nat }}\right)$ decresce de apenas $0,1 \%$ em relação à proporção observada por ocasião do uso da vazão observada $\left(\mathrm{Q}_{7,10}\right.$ observada), em algumas estações este declínio foi bem mais acentuado, atingindo até $15,7 \%$ na estação Fazenda Barra da Égua, onde a relação $\left(\mathrm{Q}_{\text {irr }} / \mathrm{Q}_{7,10 \text { obs }}\right)$ era de $85,1 \%$ e passou para $69,4 \%$ quando da consideração da relação $\left(\mathrm{Q}_{\text {irr }} / \mathrm{Q}_{7,10 \text { nat }}\right)$, valor ainda muito superior à vazão máxima passível de outorga.

Apresentam-se, na Figura 5, as vazões de retirada para irrigação no mês de maior demanda (agosto) de 1996, a $Q_{95}$ estimada com base nas vazões observadas no período de 1970 a 1996 e nas porcentagens das vazões de retirada em relação às $\mathrm{Q}_{95}$ verificadas. Nesta figura, evidencia-se que as porcentagens da vazão de retirada pela irrigação em relação à $\mathrm{Q}_{95}$ observada, variaram de 2,7 a 47,0\% nas seções analisadas, percentuais inferiores aos obtidos em relação à $\mathrm{Q}_{7,10}$, tanto aquela calculada com base em dados observados quanto a obtida com base em dados naturais.

$\mathrm{Na}$ estação Porto Alegre a vazão retirada pela irrigação correspondeu a apenas $13,7 \%$ da $\mathrm{Q}_{95}$ observada, sendo este valor inferior 1,4 vez ao obtido em comparação com a $Q_{7,10}$ verificada (19,5\%). Na estação Fazenda Barra da Égua, a vazão retirada para irrigação correspondeu a $47 \%$ da $\mathrm{Q}_{95}$ observa$\mathrm{da}$, sendo aproximadamente duas vezes inferior quando da comparação com a $\mathrm{Q}_{7,10}$ observada $(85,1 \%)$.

\section{CONCLUSÕES}

1. A vazão total consumida na bacia apresentou pouca influência na vazão média de longa duração, sendo a maior porcentagem da vazão consumida em relação à vazão média de longa duração igual a 2,1\%, observada no ribeirão Entre Ribeiros, o que potencializa a construção de reservatório na bacia.

2. Na situação mais extrema, correspondente à estação localizada no ribeirão Entre Ribeiros, a vazão de retirada pela irrigação no mês de maior demanda representou $85,1 \%$ da $\mathrm{Q}_{7,10}$ observada e 69,4\% da $\mathrm{Q}_{7,10}$ natural.

3. Para condição crítica, relativa à estação situada no ribeirão Entre Ribeiros, a vazão de retirada pela irrigação no mês de maior demanda representou 47,0\% da $\mathrm{Q}_{95}$.

\section{LITERATURA CITADA}

Alem Sobrinho, P.; Tsutiya, M.T. Coleta e transporte de esgoto sanitário. São Paulo: Departamento de Engenharia Hidráulica e Sanitária da Escola Politécnica da Universidade de São Paulo, 1999. 548p.

ANA - Agência Nacional de Águas. A evolução da gestão dos recursos hídricos no Brasil. Brasília: ANA 2002. 64p. Edição comemorativa do Dia Mundial da Água.

ANA - Agência Nacional de Águas. Memorial descritivo do cálculo da demanda humana de água contidas no documento "Base de referência do plano nacional de recursos hídricos". Brasília: Superintendência de Outorgas da Agência Nacional de Águas, 2003. 30p. Nota Técnica 010/ SPR/2003.

Brasil. Governo Federal. Minas Gerais; Governo do Estado. Distrito Federal. Plano Diretor de Recursos Hídricos da Bacia do Rio Paracatu - PLANPAR. [S. 1.]: Belo Horizonte, 1996. v.1, T. 1. CD-Rom. 
CORSAN - Companhia Riograndense de Saneamento. PróGuaíba: Esgotamento sanitário da Bacia hidrográfica do Guaíba. [S. 1.: s. n.]: Secretaria do Interior de Obras Públicas, 1991.

Dino, K.J. Projeto marca d'água: Relatórios preliminares 2001. Brasília: FINATEC, 2002, 47p.

Doorenbos, J.; Pruitt, W.O. Las necessidades de agua de los cultivos.. Roma: Food and Agriculture Organization of the United Nations, 1977. 144p. FAO Irrigation and Drainage, paper, 24.

IBGE - Instituto Brasileiro de Geografia e Estatística. Censo demográfico, Rio de Janeiro: IBGE, 1991, 512p.

IBGE - Instituto Brasileiro de Geografia e Estatística. Censo agropecuário, Rio de Janeiro: IBGE, 1996, CD- Rom.

IBGE - Instituto Brasileiro de Geografia e Estatística. Censo Demográfico, Rio de Janeiro: IBGE, 2000, CD- Rom.

Lima, J.E.F.W.; Ferreira, R.S.A.; Christofidis, D. Estudo do uso da água e energia elétrica para irrigação no Brasil. In: Encontro das Águas, 2, 1999, Montevidéu. Resumos... Montevidéu: IICA, 1999, CD-Rom.
MMA - Ministério do Meio Ambiente. Base de referência do plano nacional de recursos hídricos. http://www.mma.gov.br/ port/srh/pnrh/ documento/docbase/agrop.doc. 15 Mar. 2003.

Pereira, S.B. Evaporação no lago Sobradinho e disponibilidade hídrica no rio São Francisco. Viçosa: UFV, 2004. 103p. Tese Doutorado

Ramos, M.M.; Pruski, F.F. Subprojeto 4.3 - Quantificação e análise da eficiência do uso da água pelo setor agrícola na bacia do São Francisco. In: Projeto gerenciamento integrado das atividades desenvolvidas em terra na bacia do São Francisco. Viçosa: UFV; ANA/GEF/PNUMA/OEA, 2003. 190p. Relatório Final

Rebouças, A.C., Braga, B., Tundisi, J.G. Águas doces no Brasil: capital ecológico, uso e conservação. São Paulo: Escrituras, 1999, 717p.

Rodriguez, R. del G. Metodologia para estimativa das demandas e disponibilidades hídricas: Estudo de caso da bacia do Paracatu. Viçosa: UFV, 2004. 103p. Dissertação Mestrado 